\title{
The Impact of Volunteering on Seniors' Health and Quality of Life: An Assessment of the Retired and Senior Volunteer Program
}

\author{
Theodore W. McDonald ${ }^{1}$, Erica L. Chown ${ }^{2}$, Jordan E. Tabb ${ }^{2}$, \\ Amy K. Schaeffer ${ }^{2}$, Elsa K. M. Howard ${ }^{1}$ \\ ${ }^{1}$ Department of Community and Environmental Health, Boise State University, Boise, USA \\ ${ }^{2}$ Department of Psychology, Boise State University, Boise, USA \\ Email: tmcdonal@boisestate.edu
}

Received December 21 ${ }^{\text {st }}$ 2012; revised January $15^{\text {th }}$, 2013; accepted February $18^{\text {th }}, 2013$

\begin{abstract}
Past research suggests that senior citizens often face challenges related to deteriorating physical and mental health, and the quality of their lives may suffer as a result. Past research also suggests that volunteering can improve the health and quality of life for seniors. In the present study, 451 volunteers enrolled in the Retired and Senior Volunteer Program (RSVP) completed surveys including questions regarding their volunteer experiences and how these experiences have affected their health and quality of life. The results suggest that volunteering through RSVP is associated with improvements in health and quality of life across a variety of dimensions. Furthermore, these improvements may be particularly greater for women, current volunteers, and older seniors. These findings may help guide interventions designed to enhance the health and well-being of senior citizens in a variety of settings.
\end{abstract}

Keywords: Health; Quality of Life; Seniors; Volunteering; Self-Worth; Gender Differences

\section{Introduction}

The population of senior citizens in the United States has grown rapidly in the last century. Whereas persons aged 65 years or older comprised just over $4 \%$ of the American population at the start of the 20th century, they currently comprise nearly $13 \%$, and this percentage is expected to grow substantially in the coming decades (Administration on Aging, 2010; Arazi, 2011; Blakemore, Washington, \& McNeely, 1995; Harper, 1995; Steffen, 1996). Unfortunately, although demographers have recognized for decades that seniors will become such a large percentage of the population, some scholars (e.g., Depp \& Jeste, 2009; Duffy \& Wong, 2003; Steffen, 1996) have noted that research on seniors and on issues important to serving this population has not kept pace. In other words, as the population of seniors continues to grow, it can be fairly argued that insufficient research on healthy aging has been conducted. It seems a fair assessment to state that more high quality research should be conducted to determine what physical and mental health problems are associated with the aging process, and to use this information to develop programs, services, and interventions to address these problems and to improve seniors' quality of life (Duffy \& Wong, 2003; He, Sengupta, Veloff, \& DeBarros, 2005; Hughes et al., 2011; Parker \& Thorslund, 2007).

It has long been recognized that a decline in physical health tends to accompany the aging process (Beswick et al., 2008; Nuñez, Armbruster, Phillips, \& Gale 2003; Payette et al., 2011). Seniors, relative to younger persons, are much more likely to experience a number of physical health problems, including arthritis, coronary heart disease, diabetes, hypertension, stroke, and vision problems (Aris \& Draman, 2007; Centers for Disease Control and Prevention [CDC], 2007). Some of these problems may be associated with actual physical deterioration that occurs with age (for example, hardening of the arteries), however, at least a substantial portion of the variance in whether seniors develop such problems may be accounted for by other factors. For example, a number of researchers have noted that many seniors adopt a fairly sedentary lifestyle after retirement, rather than remaining active in the community. These researchers have argued that the sedentary lifestyle, rather than strictly the biological process of aging, may be largely responsible for an increase in health problems (CDC, 2001, 2011; Minkler, Schauffler, \& Clements-Nolle, 2000; Resnick, 1998; Resnick et al., 2006; Phillips, Pruitt, \& King, 1996; Yates, Djousse, Kurth, Buring, \& Gaziano, 2008). This argument is further supported by a number of studies that show that physical inactivity at any age is a risk factor for the development of several types of health problems. These health problems typically include coronary heart disease, cancer, and stroke-the three most common causes of death in seniors (American Heart Association, 2005; Byers et al., 2002; CDC, 2004). Thus, it appears plausible that some of the physical health problems that are commonly associated with aging are not simply age-related problems, but are caused in part by another factor-namely physical inactivity - that is associated with both aging and physical health problems.

It has also been recognized that senior citizens may be at greater risk than younger persons of certain mental health problems. According to a press release from the University of California-Irvine Medical Center (2006), depression is clearly the most prevalent mental health problem in senior citizens, followed by anxiety disorders. Other researchers have also confirmed the prevalence of these two mental health problems (e.g., Andreescu et al., 2007; Batterham, Christensen, \& Mackinnon, 2012; Dunner, 2003; Lenze et al., 2003; Vink, Aartsen, \& Schoevers, 2008; Waern, Rubenowitz, \& Wilhelmson, 2003). The prevalence of depression among seniors may be one reason 
why suicide rates among senior citizens are the highest for any age group in the United States (persons over the age of 65 years account for $18 \%$ of all suicides in the US, although this age group comprises less than $13 \%$ of the population; He et al., 2005). Researchers have identified numerous factors that might lead to high rates of depression in seniors. These factors include deteriorating physical health (Brewer et al., 2004; Fiske, Wetherell, \& Gatz, 2009; Kivela, Viramo, \& Pahkala, 2000; Vink et al., 2008; Wrosch, Schultz, \& Heckhausen, 2004), loss of significant others (Blazer, 2009; Fiske et al., 2009; Parkes, 1992; Stroebe, Schut, \& Stroebe, 2007), social isolation (Golden et al., 2009; Mireault \& de Man, 1996; Muller-Spahn \& Hock, 1994), a decreased sense of self worth, lack of meaning and purpose (Low \& Molzahn, 2007; Mascaro \& Rosen, 2008; Mossey, 1995), and even a lack of exercise (De Moor, Beem, Stubbe, Boomsma, \& De Geus, 2006; Hamer, Bates, \& Mishra, 2011; Pierce \& Pate, 1994; Singh, Clements, \& Fiatrone-Singh, 2001; Sjosten \& Kivela, 2006). Overall, it seems that, although the physical deterioration commonly associated with aging is a risk factor for depression, a number of other psychosocial variables, including several that can be addressed through preventative interventions, also predict depression in seniors.

Quality of life, which is generally defined as an individual's satisfaction with his or her own life (Hendry \& McVittie, 2004), is a construct that has recently received interest as an outcome variable in a variety of populations, including seniors (Friedman, Parikh, Guinta, Fahs, \& Gallo, 2011; Low \& Molzahn, 2007; Netuveli \& Blane, 2008; Potter, Ellard, Rees, \& Thorogood, 2011; Wilhelmson, Andersson, Waern, \& Allebeck, 2005). Although much past research has focused on the extent to which seniors' physical health affects their quality of life (Bowling \& Gabriel, 2004; Strand, 2001), this relationship is somewhat problematic in that community health professionals and other interventionists are limited in the extent to which they can arrest the physical deterioration that naturally accompanies aging. Furthermore, some researchers have found that the emphasis placed on the impact of physical health as a determinant of seniors' quality of life may be misplaced. For example, Edwards and his colleagues (Edwards et al., 2003), in a study of factors predicting quality of life in a large sample of mostly low-income seniors, found that physical health did not emerge as a significant predictor of quality of life perceptions (similar findings were reported more recently by Hall, Chui, Williams, Clark, \& Araujo, 2011). They did find that quality of life perceptions were significantly predicted by sense of life meaningfulness, level of concern shown by family, self-reported mental health status, and hours spent in social interaction. Other studies have found that personal and community relationships and perceived societal reciprocity (Lowenstein, Katz, \& Gur-Yaish, 2007; Mellor et al., 2008; Street \& Burge, 2012; Van Willigen, 2000; Wiggins, Higgs, Hyde, \& Blane, 2004) are major indicators of a senior's quality of life. Thus, it seems that seniors' quality of life is affected by a number of variables that can be influenced by interventions, as well as possibly by the physical health problems commonly associated with aging.

Many community health professionals have professed an interest in helping to improve seniors' physical health, mental health, and quality of life. One way that some researchers believe these goals can be accomplished is to help seniors remain active in the community through volunteering, which may serve as a preventative tool against many of the problems associated with aging (Adelmann, 1994; Fengler, 1984; Komp, van Til- burg, \& van Groenou, 2012; Musick \& Wilson, 2003; Young \& Glasgow, 1998). Indeed, some research has shown that volunteering provides a socially rewarding and physically active environment that greatly benefits seniors (Cattan, Hogg, \& Hardill, 2011; Piliavin, 2003; Van Willigen, 2000; Warburton, Paynter, \& Petriwskyj, 2007). Research by Musick and Wilson (2003) and by Rietchlin (1998) suggests that volunteering may help reduce psychological distress-particularly symptoms of depression-in volunteers, and that seniors may benefit more from the experience than members of other age groups. Musick, Herzog, and House (1999), in a study featuring a large, representative sample of seniors, reported that volunteering may even reduce mortality among seniors (for additional research on the relationship between volunteering and mortality, see Oman, Thorensen, \& McMahon, 1999). Interestingly, Rietchlin (1998) maintains that formal volunteering leads to a stress-buffering effect, in which individuals are able to withstand stressful experiences better due to volunteer participation. Other researchers maintain that volunteering may benefit seniors primarily by offering opportunities for physical activity and social interaction (Fengler, 1984; Mellor et al., 2008; Morrow-Howell, 1989; Tang, 2009). Furthermore, volunteering has been conceptualized as a positive and organized activity that fills the void of structure created by retirement (Hank \& Erlinghagen, 2010; Van Willigen, 2000; Wilhelmson et al., 2005). It may also help seniors to feel that they are continuing to make a meaningful contribution to society, thus helping to develop and maintain a healthy sense of self-worth, sense of accomplishment, and confidence (Babic, 1972; Komp et al., 2012; Martinson \& Minkler, 2006; Morrow-Howell, 1989). Each of these individual benefits may contribute to a synergistic combination that positively improves seniors' overall health and quality of life. Finally, it is difficult to argue that encouraging seniors to volunteer can be enormously beneficial to organizations that work with them, as seniors often possess marketable skills accumulated from a lifetime of employment and are available more often and for longer periods of time (Babic, 1972; Bowman, 2009, Principi, Lindley, Perek-Bialas, \& Turek, 2012). Thus, the encouragement of senior volunteering creates a mutually beneficial relationship in which the volunteer organizations benefit from a plentiful source of qualified volunteers, and the seniors benefit from the structured environment that provides socialization and physical activity (Morrow-Howell, 2010; Tang, Choi, \& Morrow-Howell, 2010).

The purpose of the present study was to assess the benefits of volunteering on seniors across a variety of domains. Although, as discussed above, several research studies have focused on the relationship between volunteering and certain important outcome indicators, they have rarely focused on many outcomes. Thus, this study contributes to the scientific literature by assessing how volunteering may help improve seniors' lives in a number of ways, and focuses particularly on physical and mental health, as well as quality of life. The study itself was initiated in response to a request from two regional directors of the Retired and Senior Volunteer Program (RSVP). RSVP is one of three programs federally administered in the US through the Senior Corps, and coordinates volunteering opportunities for individuals aged 55 and older at thousands of sites (Senior Corps, 2012). RSVP coordinates opportunities that include working with children and schools, providing administrative support to non-profit organizations, building homes and tending community gardens, serving in neighborhood watch and com- 
munity development organizations, and providing disaster relief, among others. In return for services provided, volunteers receive training for their position, supplemental insurance while volunteering, and reimbursement for travel expenses incurred while volunteering (Senior Corps, 2012).

As described in detail below, the study involved surveying all RSVP volunteers in two administrative regions in southwestern Idaho. Volunteers were asked to comment on the extent to which participating in RSVP and volunteering in their communities had affected their lives across a number of domains. We hypothesized that the survey respondents would report improvement in all measured areas of their lives as a result of volunteering, and particularly in terms of their physical health, mental health, and perceived quality of life.

\section{Method}

\section{Participants}

The participants in this study were 451 individuals who were enrolled as RSVP volunteers in two RSVP administrative regions located in southwestern Idaho. The majority of the participants $(74.9 \%)$ reported being women, and the median age was 77 years (with a range from 43 to 97 years). The median length of service as a RSVP volunteer was 48 months (with a range from less than one month to 540 months). The vast majority $(92.5 \%)$ of the respondents reported currently volunteering during the year the study was conducted.

\section{Materials}

The materials utilized in this study were individual survey packets containing a cover letter, an attached three-page survey, and a postage-paid return envelope. The cover letter was addressed to potential study participants, and signed by the directors of the two regional RSVP programs. This cover letter invited RSVP volunteers to complete the attached survey as part of an ongoing program evaluation effort, and stressed that completion of the survey was strictly voluntary and anonymous. The actual survey was based primarily on an unpublished template created by national RSVP administrators, which had been made available to RSVP regional directors across the United States. The survey that was utilized in this study contained several demographic items concerning participant age, gender, length of RSVP volunteer service, and current volunteering status. The survey also contained several items designed to assess whether volunteering with RSVP had led to changes in a variety of aspects of the participants' lives. Specifically, the respondents were asked to indicate whether participation with RSVP had resulted in changes in the participants': 1) sense of accomplishment; 2) feeling that they have a purpose in life; 3) feeling they can make a positive difference in another person's life; 4) looking forward to each new day; 5) amount of pleasure gained from their daily activities; 6) sense of self-worth; 7) perceived physical health; 8) perceived psychological health; 9) overall sense of well-being; and 10) overall quality of life. The response format for all of these items featured five-point Likert-type scales. These scales measured levels of life change that respondents had experienced since they began volunteering. The scales also measured the nature of any perceived changes. The values on the scale included: $1=$ It's a lot worse (i.e., an aspect of my life is a lot worse since I began volunteering through RSVP); 2 = It's worse; 3 = No change (i.e., this aspect of my life has not changed since I began volunteering through RSVP); 4) It's better; and 5 = It's a lot better.

\section{Procedure}

The research team and the two RSVP regional directors collaborated in order to create the survey instrument that was used in this study. Some of the survey items were gleaned from the unpublished RSVP program evaluation template and some new items were added that were believed to be useful for the final survey. The RSVP regional directors provided the research team with printed address labels for all of the RSVP volunteers that were currently enrolled in their regions. Members of the research team affixed these labels to envelopes containing the cover letter, survey, and a self-addressed postage-paid envelope that the participants could use to mail the surveys back to the researchers. A total of 1661 surveys were mailed to RSVP volunteers. Eighty-four surveys were returned to sender, thus 1577 appeared to reach the desired volunteers. A total of 451 RSVP volunteers completed and returned the surveys, for a valid response rate of $28.6 \%$.

\section{Results}

The primary purpose of this project was to determine whether volunteering in the RSVP program had led to changes in the volunteers' lives; thus the primary analysis utilized onesample t-tests to assess whether the participants' mean scores on the 10 Likert-scale items differed from the scale value of 3, which indicated 'No change'. As seen in Table 1, statistically significant mean differences (from the scale value of 3) were found on all 10 items, with each item being statistically significant at the $p<.001$ level. In addition, all means for the 10 items were above the scale value of 3 (see Table 1), meaning that the participants felt that 10 distinct elements of their lives had improved since beginning volunteering through RSVP. Specifically, respondents reported perceiving that their sense of accomplishment, life purpose, ability to make a difference in another person's life, looking forward to each new day, pleasure gained from daily activities, sense of self-worth, physical health, psychological health, overall sense of well-being, and overall quality of life had all improved significantly since they had begun volunteering in the RSVP program.

Although the primary purpose of this project was to determine whether volunteering through RSVP led to changes in the lives of volunteers as a whole, it was determined that an assessment of the differential changes that respondents may have experienced as a result of volunteering would also be valuable. In particular, we were interested in assessing whether men and women reported different degrees of life change as a function of their volunteering experiences with RSVP. As seen in Table 2, statistically significant differences as a function of gender were found on perceived changes for all 10 elements of life, with women reporting significantly more positive changes on all 10 elements. Therefore, although both men and women reported that volunteering through RSVP had led to significantly positive changes on all measured dimensions, these changes were significantly greater for women than they were for men.

A third set of analyses was conducted in order to assess whether current RSVP volunteers (i.e., participants who reported volunteering during the study year) and non-current RSVP volunteers (i.e., participants who reported volunteering in the 
Table 1.

Perceived life changes as a function of volunteering through RSVP.

\begin{tabular}{lccc}
\hline Question: To what extent has volunteering resulted in a change of your & M & Mean Difference from 3 (No Change) & t \\
\hline Sense of accomplishment & 4.20 & 1.20 & $35.46^{* * *}$ \\
Feeling that you have a purpose in life & 4.17 & 1.17 & $33.34^{* * *}$ \\
Feeling that you can make a positive difference in another person's life & 4.23 & 1.23 & $38.38^{* * *}$ \\
Looking forward to each new day & 4.03 & 1.03 & $27.35^{* * *}$ \\
Amount of pleasure you gain from your daily activities & 4.11 & 1.11 & $30.89^{* * *}$ \\
Sense of self-worth & 4.12 & 1.12 & $29.89^{* * *}$ \\
Perceived physical health & 3.39 & 0.39 & $9.62^{* * *}$ \\
Perceived psychological health & 3.74 & 0.74 & $20.08^{* * *}$ \\
Sense of overall well-being & 3.85 & 0.85 & $22.76^{* * *}$ \\
Overall quality of life & 3.85 & 0.85 & $22.92^{* * * *}$ \\
\hline
\end{tabular}

Note: All means are on a 5-point scale with higher values indicating more positive change. ${ }^{* * *}$ denotes statistical significance at the $p<.001$ level.

Table 2.

Perceived life changes resulting from volunteering through volunteering as a function of gender.

\begin{tabular}{|c|c|c|c|c|c|}
\hline \multirow[t]{2}{*}{ Question: To what extent has volunteering resulted in a change of your } & \multicolumn{2}{|c|}{ Female } & \multicolumn{2}{|c|}{ Male } & \multirow[t]{2}{*}{$t$} \\
\hline & $M$ & $S D$ & $M$ & $S D$ & \\
\hline Sense of accomplishment & 4.27 & .68 & 3.99 & .72 & $3.66^{* *}$ \\
\hline Feeling that you have a purpose in life & 4.25 & .72 & 3.92 & .71 & $4.24^{* *}$ \\
\hline Feeling that you can make a positive difference in another person's life & 4.27 & .67 & 4.12 & .62 & $2.02^{*}$ \\
\hline Looking forward to each new day & 4.10 & .78 & 3.83 & .74 & $3.16^{* *}$ \\
\hline Amount of pleasure you gain from your daily activities & 4.17 & .74 & 3.94 & .74 & $2.80^{* *}$ \\
\hline Sense of self-worth & 4.19 & .76 & 3.92 & .79 & $3.21^{* *}$ \\
\hline Perceived physical health & 3.46 & .82 & 3.18 & .84 & $3.05^{* *}$ \\
\hline Perceived psychological health & 3.78 & .76 & 3.61 & .73 & $2.00^{*}$ \\
\hline Sense of overall well-being & 3.91 & .74 & 3.65 & .80 & $3.06^{* *}$ \\
\hline Overall quality of life & 3.91 & .74 & 3.68 & .80 & $2.81^{* *}$ \\
\hline
\end{tabular}

Note: All means are on a 5 -point scale with higher values indicating a more positive change. ${ }^{* *}$ denotes statistical significance at the $p<.01$ level and ${ }^{*}$ denotes statistical significance at the $p<.05$ level.

past, but not during the study year) differed significantly in the extent to which they felt their lives had changed as a function of volunteering through RSVP. Statistically significant differences in perceived life changes were found between current and non-current volunteers on four of the 10 elements of life; sense of accomplishment, feeling that one can make a difference in another person's life, the amount of pleasure gained from daily activities, and sense of self-worth. The first finding was accounted for by current RSVP volunteers $(\mathrm{M}=4.22$, SD = .69) reporting a perception of significantly more positive change in sense of accomplishment as a function of volunteering than non-current volunteers $(\mathrm{M}=3.89, \mathrm{SD}=.85), \mathrm{t}(424)=2.36, p$ $<.05$. The second finding was accounted for by current volunteers $(\mathrm{M}=4.25, \mathrm{SD}=.66)$ reporting perceiving significantly more positive change in the feeling that they can make a positive difference in another person's life than non-current volunteers $(\mathrm{M}=3.89, \mathrm{SD}=.64), \mathrm{t}(420)=2.73, p<.01$. The third finding was accounted for by current volunteers $(\mathrm{M}=4.12$, SD $=.75$ ) reporting perceiving significantly more positive change in the amount of pleasure gained from daily activities than non-current volunteers $(\mathrm{M}=3.82, \mathrm{SD}=.72), \mathrm{t}(424)=2.07, p$
$<.05$. The fourth finding was accounted for by current volunteers $(\mathrm{M}=4.14, \mathrm{SD}=.76)$ reporting perceiving significantly more positive change in their sense of self-worth than noncurrent volunteers $(\mathrm{M}=3.76, \mathrm{SD}=.91)$, t $(420)=2.59, p<.01$. Overall, the results of these analyses provide support for the notion that current volunteers may reap more benefits from volunteering than persons who volunteered in the past, but are no longer volunteering.

The final analyses that were conducted were intended to determine whether the age of the volunteer was systematically related to perceived changes on the 10 elements of life. Correlational analyses pairing age and each of the 10 elements of life were conducted, and statistically significant relationships were found on five of the elements of life. It was found that volunteer age was significantly and positively associated with: 1) an increase in sense of accomplishment as a result of volunteering $(\mathrm{r}[\mathrm{N}=425]=.15, p<.01) ; 2)$ feeling that one has an increased sense of purpose as a result of volunteering $(\mathrm{r}[\mathrm{N}=427]=.17$, $p<.001$ ); 3) increased looking forward to each new day as a result of volunteering $(\mathrm{r}[\mathrm{N}=422]=.15, p<.01)$; 4$)$ increased pleasure gained from daily activities as a result of volunteering 
$(\mathrm{r}[\mathrm{N}=425]=.12, p<.05)$; and 5$)$ increased sense of self-worth as a result of volunteering $(\mathrm{r}[\mathrm{N}=421]=.12, p<.05)$. Thus, it seems that at least some of the positive impacts of volunteering may be greater for older volunteers than for younger volunteers.

\section{Discussion}

In this study, we found that seniors who volunteered through the RSVP program reported that a number of elements of their lives had improved significantly since they began volunteering through the program. As noted earlier, we were particularly interested in the extent to which volunteering had influenced the seniors' perceived physical health, mental health, and quality of life. The results clearly showed that the seniors felt better physically and mentally since they began volunteering, and they felt that their overall quality of life had improved as well. In addition to these three constructs, we were also interested in assessing whether volunteering had affected other areas of survey respondents' lives. We found that the seniors believed volunteering through RSVP had significantly improved their lives on every other possible dimension-giving their lives purpose, providing them with a sense that they can make a positive difference in another person's life, helping them look forward to each new day, increasing the amount of pleasure gained from daily activities, increasing their sense of self-worth, and increasing their sense of overall well being. Overall, the survey respondents clearly believed that their lives were better due to their volunteer experiences with RSVP. The results of this study appear to offer extremely strong support for the notion that volunteering is a beneficial activity in which seniors can engage.

In this study, we also found that the benefits of volunteering seemed particularly pronounced for women, older volunteers, and those respondents who were currently volunteering during the year the study was conducted. The findings concerning gender merit particular interest, as we found that women reported the positive effects of volunteering to be greater than men on all 10 elements of their lives (differential benefits as a function of gender were also reported by Ahern \& Hendryx, 2008). These findings seem to raise several important questions. For example, why might volunteering benefit women more than men? How might the practice or experience of volunteering be modified to have a greater benefit for men? The first question might be answered, at least in part, by recognizing that volunteering offers opportunities for social interaction and therefore the development and use of social support. Certainly, studies in the scientific literature (e.g., Belle, 1991; Denton, Prus, \& Walters, 2004; Rosario, Shinn, Morch, \& Huckabee, 1988; Wymer, 2012) exist which suggest that women tend to utilize social support differently than men. Simply stated, women tend to have larger and stronger social support systems, and they tend to access and rely on them more frequently (Belle, 1991; Wymer, 2012). Thus, it could be that women benefit more from volunteering than men because women tend to maximize opportunities to create and access social supports. The second question, regarding how to improve the practice or experience of volunteering for men, may be more difficult to answer. A first step that is important to consider when attempting to answer this question may be to further explore why men report benefiting from volunteering less than women. Such further exploration seems warranted, as the answers obtained would surely help volunteer coordinators to more effectively recruit and retain male volunteers.

The finding that older volunteers tended to report more benefits from volunteering than younger volunteers also merits attention, particularly with respect to its implications. As discussed earlier, the aging process tends to be associated with increased morbidity and mortality, as well as a decreased quality of life. Any activity that might lead to particularly positive results for older seniors seems desirable to encourage, and volunteering may be a suitable choice. Of course, it should be recognized that volunteering coordinators might have to be increasingly creative in developing volunteering opportunities for older seniors, as many of these seniors may have greater difficulties associated with transportation, physical mobility, and so forth. However, to the extent that volunteer coordinators truly care about the well-being of older seniors, such efforts appear likely to be successful in making life more healthy and enjoyable for them. The last finding, that current volunteers reported greater benefits from volunteering than past, noncurrent volunteers, also warrants consideration, although it is somewhat more difficult to interpret. This finding superficially suggests that discontinuing volunteering activities may lead to a gradual reduction in the benefits of volunteering. If this is true, then this finding has valuable implications regarding the importance of volunteer retention efforts. However, the possibility exists that non-current volunteers are no longer volunteering due to recent health problems, which may also consequently explain why non-current volunteers reported fewer benefits from volunteering than did current volunteers.

Although the results of this study seem both strong and useful, we should note several limitations of the research. First, the use of a "retrospective" survey design, or one that asks survey respondents to remember their perceptions or feelings at an earlier point in time, is inherently limited. When using this design, we are forced to assume that people can accurately recall how they felt (in terms of their physical health, feeling of life purpose, and so forth) prior to beginning volunteering through RSVP, in order to fairly compare their pre-volunteering perceptions to their perceptions after having volunteered for a period of time. This type of design is not uncommon in program evaluation studies, however we do recognize the limitations of it, and also recognize that a pretest-posttest design would have been far more desirable. Second, we are cognizant of the need for caution when generalizing our results. Because we studied the effects of volunteering in a two-region area comprising 10 counties of a single state, we realize that it may not be completely appropriate to assume that the results would be the same if we had surveyed senior volunteers from RSVP programs located across the nation.

Many researchers and scholars (e.g., Duffy \& Wong, 2003; Friedman et al., 2011) have noted that seniors have been disproportionately underrepresented in the scientific literature, and because seniors are such a large and growing segment of the population, continued lack of focus on seniors seems decidedly unwise. It seems imperative to understand what factors influence the health and well being of seniors so that we can effectively serve this population and improve the quality of their lives. As the results of this study suggest, engaging in volunteering activities through RSVP may be one way to positively impact seniors' physical and mental health, as well as their quality of life. Therefore, it seems that it would be wise to offer greater volunteering opportunities, and engage in active outreach and recruitment efforts to encourage seniors to take ad- 
vantage of these opportunities. Although RSVP is a major, national program with numerous regional offices, there are many other existing programs that seniors can volunteer through, and an almost unlimited number of senior volunteering programs that could be developed by community and senior centers, churches and other places of worship, schools, and so forth. Many scholars and members of the general public profess to care about the health and well being of seniors. By helping seniors to engage in activities - such as volunteering-that have been demonstrated to have a positive effect on them, we can convert our compassion into action.

\section{Acknowledgements}

This research project was supported by a $\$ 400$ teaching grant to the first author from the College of Social Sciences and Public Affairs at Boise State University. The authors wish to thank Elizabeth A. LeMesurier, Komal Mehrotra, and Abel Morel for their help with data collection and entry, and Lisa A. Mackenzie for reviewing and editing this work.

\section{REFERENCES}

Adelmann, P. K. (1994). Multiple roles and physical health status among older adults: Gender and ethnic comparisons. Research on Aging, 16, 142-166. doi:10.1177/0164027594162002

Administration on Aging (2010). Aging statistics.

http://www.aoa.gov/aoaroot/aging_statistics/index.aspx

Ahern, M. M., \& Hendryx, M. (2008). Community participation and the emergence of late-life depressive symptoms: Differences between women and men. Journal of Women's Health, 17, 1463-1470. doi:10.1089/jwh.2007.0752

American Heart Association, Inc. (2005). Risk factors and coronary heart disease.

http://www.americanheart.org/presenter.jhtml?identifier=500

Arazi, B. (2011). Enhancing elderly utilization of social networks. International Journal on Disability and Human Development, 8, 199206. doi:10.1515/IJDHD.2009.8.3.199

Aris, M. A. M., \& Draman, S. (2007). Physical and mental health problems of the elderly in nursing homes in Kuantan, Pahang. International Medical Journal, 6. URL (last checed 31 December 2010). http://www.eimjm.com/Vol6-No1/Vol6-No1-B4.htm

Babic, A. L. (1972). The older volunteer: Expectations and satisfactions. Gerontologist, 12, 87-90. doi:10.1093/geront/12.1_Part 1.87

Batterham, P. J., Christensen, H., \& Mackinnon, A. J. (2012). Mental health symptoms associated with morbidity, not mortality, in an elderly community sample. Social Psychiatry and Psychiatric Epidemiology, 47, 79-85. doi:10.1007/s00127-010-0313-0

Belle, D. (1991). Gender differences in the social moderators of stress. In A. Monat, \& R. S. Lazarus (Eds.), Stress and coping: An anthology (pp. 258-274). New York: Columbia University Press.

Beswick, A. Rees, K., Dieppe, P., Ayis, R., Gooberman-Hill, R., Horwood, J., \& Ebrahim, S. (2008). Complex interventions to improve physical function and maintain independent living in elderly people: A systematic review and meta-analysis. The Lancet, 371, 725-735. doi:10.1016/S0140-6736(08)60342-6

Blakemore, J. L., Washington, R. O., \& McNeely, R. L. (1995). The demography of aging. In P. K. H. Kim (Ed.), Services to the aging and aged: Public policies and programs. New York: Garland.

Blazer, D. G. (2009). Depression in late life: Review and commentary. Focus, 7, 118-136.

Bowling, A., \& Gabriel, Z. (2004). An integrational model of quality of life in older age: Results from the ESRC/MRC HSRC quality of life survey in Britain. Social Indicators Research, 69, 1-36. doi:10.1023/B:SOCI.0000032656.01524.07

Bowman, W. (2009). The economic value of volunteers to nonprofit organizations. Nonprofit Management and Leadership, 19, 491-506. doi:10.1002/nml.233
Brewer, K. C., Taylor, K. C., Dawson, E. S., Foster, R., Gull, K. L., Haber, J. D., \& McDonald, T. W. (2004). Factors related to mental health status in senior citizens. The Annual Meeting of the Rocky Mountain Psychological Association, Reno, NV.

Byers, T., Nestle, M., McTiernan, A., Doyle, C., Currie-Williams, A., Gansler, T., Thun, M., \& The American Cancer Society 2001 Nutrition and Physical Activity Guidelines Advisory Committee (2002). American cancer society guidelines on nutrition and physical activity for cancer prevention. http://caonline.amcancersoc.org/cgi/content/full/52/2/92

Cattan, M., Hogg, E., \& Hardill, I. (2011). Improving quality of life in ageing populations: What can volunteering do? Maturitas, 70, 328332. doi:10.1016/j.maturitas.2011.08.010

Centers for Disease Control and Prevention (2001). Healthy aging: Preventing disease and improving quality of life among older Americans: 2001 At-a-glance report.

http://www.cdc.gov/scientific.htm

Centers for Disease Control and Prevention (2007). The state of aging and health in America.

http://www.cdc.gov/Aging/pdf/saha_2007.pdf

Centers for Disease Control and Prevention (2011). Healthy aging: Helping people to live longer and productive lives and enjoy a good quality of life: 2011 At-a-glance report.

http://www.cdc.gov/chronicdisease/resources/publications/AAG/agin g.htm

De Moor, M. H. M., Beem, A. L., Stubbe, J. H., Boomsma, D. I., \& De Geus, E. J. E. (2006). Regular exercise, anxiety, depression, and personality: A population-based study. Preventive Medicine, 42, 273279. doi:10.1016/j.ypmed.2005.12.002

Depp, C. A., \& Jeste, D. V. (2009). Definitions and predictors of successful aging: A comprehensive review of larger quantitative studies. Focus, 7, 137-150.

Denton, M., Prus, S., \& Walters, V. (2004). Gender differences in health: A Canadian study of the psychosocial, structural, and behavioural determinants of health. Social Science \& Medicine, 58, 25852600. doi:10.1016/j.socscimed.2003.09.008

Duffy, K. G., \& Wong, F. Y. (2003). Community psychology. Boston, MA: Allyn and Bacon.

Dunner, D. L. (2003). Anxiety and depression in the elderly: Implications for diagnosis and treatment. CNS Spectrums, 8, 5.

Edwards, J. K., Baker, V. L., Mathisen, L. E., Murray, D. L., \& Shackelford, T. I., \& McDonald, T. W. (2003). Predicting seniors' quality of life in the intermountain west. The Annual Meeting of the Rocky Mountain Psychological Association, Denver, CO.

Fengler, A. P. (1984). Life satisfaction of subpopulations of elderly: The comparative effects of volunteerism, employment, and meal site participation. Research on Aging, 6, 189-212. doi:10.1177/0164027584006002003

Fiske, A., Wetherell, J. L., \& Gatz, M. (2009). Depression in older adults. Annual Review of Clinical Psychology, 5, 363-389. doi:10.1146/annurev.clinpsy.032408.153621

Friedman, D., Parikh, N. S., Guinta, N., Fahs, M. C., \& Gallo, W. T. (2011). The influence of neighborhood factors on the quality of life of older adults attending New York City senior centers: Results from the Health Indicators Project. Quality of Life Research, 21, 123-131. doi:10.1007/s11136-011-9923-6

Golden, J., Conroy, R. M., Bruce, I., Denihan, A., Greene, E., Kirby, M. et al. (2009). Loneliness, social support networks, mood and wellbeing in community-dwelling elderly. International Journal of Geriatric Psychiatry, 24, 694-700. doi:10.1002/gps.2181

Hall, S. A., Chui, G. R., Williams, R. E., Clark, R. V., \& Araujo, A. B. (2011). Physical function and health-related quality-of-life in a population-based sample. The Aging Male, 14, 119-126. doi:10.3109/13685538.2010.502267

Hamer, M. Bates, C. J., \& Mishra, G. D. (2011). Depression, physical function, and risk of mortality: National Diet and Nutrition Survey in adults older than 65 years. American Journal of Geriatric Psychiatry, 19, 72-78. doi:10.1097/JGP.0b013e3181df465e

Hank, K., \& Erlinghagen, M. (2010). Dynamics of volunteering in older Europeans. The Gerontologist, 50, 170-178. doi:10.1093/geront/gnp122 
Harper, M. S. (1995). Mental health and mental health services. In P. K. H. Kim (Ed.), Services to the aging and aged: Public policies and programs. New York: Garland.

He, W., Sengupta, M., Velkoff, V. A., \& DeBarros, K. A. (2005). 65+ in the United States: 2005.

http://www.census.gov/prod/2006pubs/p23-209.pdf

Hendry, F., \& McVittie, C. (2004). Is quality of life a healthy concept? Measuring and understanding life experiences of older people. Qualitative Health Research Special Issue: Models for illness, 14, 961975. doi:10.1177/1049732304266738

Hughes, S. L., Leith, K. H., Marquez, D. X., Moni, G., Nguyen, H. Q., Desai, P., \& Jones, D. L. (2011). Physical activity and older adults: Expert consensus for a new research agenda. The Gerontologist, 51, 822-832. doi:10.1093/geront/gnr106

Kivela, S. L., Viramo, P., \& Pahkala, K. (2000). Factors predicting chronicity of depression in elderly primary care patients. International Psychogeriatrics, 12, 183-194. doi:10.1017/S1041610200006311

Komp, K., van Tilburg, T., \& van Groenou, M. B. (2012). Age, retirement, and health as factors in volunteering in later life. Nonprofit and Voluntary Sector Quarterly, 41, 280-299. doi:10.1177/0899764011402697

Lenze, E. J., Pollock, B. G., Shear, M. K., Mulsant, B. H., Bharucha, A., \& Reynolds, C. F. (2003). Treatment considerations for anxiety in the elderly. CNS Spectrums, 8, 6-13.

Low, G., \& Molzahn, A. E. (2007). Predictors of quality of life in old age: A cross-validation study. Research in Nursing \& Health, 30, 141-150. doi:10.1002/nur.20178

Lowenstein, A., Katz, R., \& Gur-Yaish, N. (2007). Reciprocity in parent-child exchange and life satisfaction among the elderly: A crossnational perspective. Journal of Social Issues, 63, 865-883. doi:10.1111/j.1540-4560.2007.00541.X

Martinson, M., \& Minkler, M. (2006). Civic engagement and older adults: A critical perspective. The Gerontologist, 46, 318-324. doi:10.1093/geront/46.3.318

Mascaro, N., \& Rosen, D. H. (2008). Assessment of existential meaning and its longitudinal relations with depressive symptoms. Journal of Social and Clinical Psychology, 27, 576-599. doi:10.1521/jscp.2008.27.6.576

Mellor, D., Hayashi, Y., Stokes, M., Firth, L., Lake, L., Staples, M., \& Cummins, R. (2008). Volunteering and its relationship with personal and neighborhood well-being. Nonprofit and Voluntary Sector Quarterly, 38, 144-159. doi:10.1177/0899764008317971

Minkler, M., Schauffler, H., \& Clements-Nolle, K. (2000). Health promotion for older Americans in the 21st century. American Journal of Health Promotion, 14, 371-379.

Mireault, M., \& de Man, A. F. (1996). Suicidal ideation among the elderly: Personal variables, stress, and social support. Social Behavior and Personality, 24, 385-392. doi:10.2224/sbp.1996.24.4.385

Morrow-Howell, N. (2010). Volunteering in later life: Research frontiers. The Journals of Geronotology: Series B, 65, 461-469. doi:10.1093/geronb/gbq024

Morrow-Howell, N. (1989). Elderly volunteers: Reasons for initiating and terminating service. Journal of Gerontological Social Work, 13, 21-34.

Mossey, J. M. (1995). Importance of self-perceptions for health status among older persons. In M. Gatz (Ed.), Emerging issues in mental health and aging (pp. 124-162). Washington DC: American Psychological Association. doi:10.1037/10179-005

Muller-Spahn, F., \& Hock, C. (1994). Clinical depression in the elderly. Gerontology, 40, 10-14. doi:10.1159/000213615

Musick, M. A., Herzog, A. R., \& House, J. S. (1999). Volunteering and mortality among older adults: Findings from a national sample. Journals of Gerontology: Series B: Psychological Sciences and Social Sciences, 54, S173-S180. doi:10.1093/geronb/54B.3.S173

Musick, M. A., \& Wilson, J. (2003). Volunteering and depression: The role of psychological and social resources in different age groups. Social Science and Medicine, 56, 259-269. doi:10.1016/S0277-9536(02)00025-4

National Stroke Association (n.d.). Public stroke prevention guidelines. http://www.stroke.org/site/PageServer?pagename=PREVENT
Netuveli, G., \& Blane, D. (2008). Quality of life in older ages. British Medical Bulletin, 85, 113-126. doi:10.1093/bmb/ldn003

Nuñez, D. E., Armbruster, C., Phillips, W. T., \& Gale, B. J. (2003). Community-based senior health promotion program using a collaborative practice model: The Escalante Health Partnerships. Public Health Nursing, 20, 25-32. doi:10.1046/j.1525-1446.2003.20104.x

Oman, D., Thoresen, C. E., \& McMahon, K. (1999). Volunteerism and mortality among the community-dwelling elderly. Journal of Health Psychology, 4, 301-316. doi:10.1177/135910539900400301

Parker, M. G., \& Thorslund, M. (2007). Health trends in the elderly population: Getting better and getting worse. The Gerontologist, 47, 150-158. doi:10.1093/geront/47.2.150

Parkes, C. M. (1992). Bereavement and mental health in the elderly. Reviews in Clinical Gerontology, 2, 45-51. doi:10.1017/S0959259800002999

Payette, H., Gueye, N. D., Gaudreau, P., Morais, Shatenstein, B., \& Gray-Donald, K. (2011). Trajectories of physical function decline and psychological functioning: The Quebec Longitudinal Study on Nutrition and Successful Aging (NuAge). The Journals of Geronotology Series B: Psychological Sciences and Social Sciences, 66, 8290. doi:10.1093/geronb/gbq085

Phillips, W. T., Pruitt, L. A., \& King, A. C. (1996). Lifestyle activity: Current recommendations. Sports Medicine, 22, 1-7. doi:10.2165/00007256-199622010-00001

Pierce, E., \& Pate, D. W. (1994). Mood alterations in older adults following acute exercise. Perceptual and Motor Skills, 79, 191-194. doi:10.2466/pms.1994.79.1.191

Piliavin, J. A. (2003). Doing well by doing good: Benefits for the benefactor. In C. L. M. Keyes, \& J. Haidt (Eds.), Flourishing: Positive psychology and the life well-lived (pp. 227-247). Washington DC: American Psychological Association. doi:10.1037/10594-010

Potter, R., Ellard D., Rees, K., \& Thorogood, M. (2011). A systematic review of the effects of physical activity on physical functioning, quality of life and depression in older people with dementia. International. Journal of Geriatric Psychiatry, 26, 1000-1011. doi:10.1002/gps.2641

Principi, A., Lindley, R., Perek-Biaslas, J., \& Turek, K. (2012). Volunteering in older age: An organizational perspective. International Journal of Manpower, 33, 685-703. doi:10.1108/01437721211261822

Resnick, B. (1998). Health promotion practices of the old-old. Journal of the American Academy of Nurse Practitioners, 10, 147-153. doi:10.1111/j.1745-7599.1998.tb01282.x

Resnick, B., Ory, M. G., Rogers, M. E., Page, P., Lyle, R. M., Sipe, C. et al. (2006). Screening for and prescribing exercise by older adults. Geriatrics and Aging, 9, 174-182.

Rietschlin, J. (1998). Voluntary association membership and psychological distress. Journal of Health and Social Behavior, 39, 348-355. doi: $10.2307 / 2676343$

Rogerson, R. J. (1995). Environmental and health-related quality of life: Conceptual and methodological similarities. Social Science \& Medicine, 41, 1373-1382. doi:10.1016/0277-9536(95)00122-N

Rosario, M., Shinn, M., Morch, H., \& Huckabee, C. B. (1988). Gender differences in coping and social supports: Testing socialization and role constraint theories. Journal of Community Psychology, 16, 55-69. doi:10.1002/1520-6629(198801)16:1<55::AID-JCOP2290160108>3. $\underline{0 . \mathrm{CO} ; 2-\mathrm{U}}$

Senior Corps (2012). Retired and Senior Volunteer Program (RSVP). http://www.seniorcorps.gov/about/programs/rsvp.asp

Sjosten, N., \& Kivela, S. L. (2006). The effects of physical exercise on depressive symptoms among the aged: A systematic review. International Journal of Geriatric Psychiatry, 21, 410-418. doi:10.1002/gps.1494

Steffen, A. M. (1996). Community psychology's response to the promises and problems of aging. The Community Psychologist, 29, 19-21.

Strand, J. A. (2001). Reexamining factors affecting quality of life perceptions among rural seniors. Unpublished manuscript, Chico, CA: California State University.

Street, D., \& Burge, S. W. (2012). Residential context, social relationships, and well-being in assisted living. Research on Aging, 34, 365394. $\underline{\text { doi: } 10.1177 / 0164027511423928}$ 
Stroebe, M., Schut, H., \& Stroebe, W. (2007). Health outcomes of bereavement. Lancet, 370, 1960-1973.

doi:10.1016/S0140-6736(07)61816-9

Singh, N. A., Clements, K. M., \& Fiatarone-Singh, M. A. (2001). The efficacy of exercise as a long-term antidepressant in elderly subjects: A random, controlled trial. Journals of Gerontology Series A: Biological Sciences and Medical Sciences, 56, M497-M504. doi:10.1093/gerona/56.8.M497

Tang, F. (2009). Late life volunteering and trajectories of physical health. Journal of Applied Gerontology, 28, 524-533. doi:10.1177/0733464808327454

Tang, F., Choi, E., \& Morrow-Howell, N. (2010). Organizational support and volunteering benefits for older adults. The Gerontologist, 50, 603-612. doi:10.1093/geront/gnq020

University of California-Irvine Medical Center (2006). Coming of age: Mental health services for older people can make life worth living again.

http://www.ucihealth.com/News?UCI20\%Health/Comingofage.htm

Van Willigen, M. (2000). Differential benefits of volunteering across the life course. Journals of Gerontology Series B: Psychological Sciences and Social Sciences, 55, S308-S318.

doi:10.1093/geronb/55.5.S308

Vink, D., Aartsen, M. J., \& Schoevers, R. A. (2008). Risk factors for anxiety and depression in the elderly: A review. Journal of Affective Disorders, 106, 29-44. doi:10.1016/j.jad.2007.06.005

Waern, M., Rubenowitz, E., \& Wilhelmson, K. (2003). Predictors of suicide in the old elderly. Gerontology, 49, 328-334. doi:10.1159/000071715

Warburton, J., Paynter, J., \& Petriwskyj, A. (2007). Volunteering as a productive aging activity: Incentives and barriers to volunteering by Australian seniors. Journal of Applied Gerontology, 26, 333-354. doi: $10.1177 / 0733464807304568$

Wiggins, R. D., Higgs, P. F. D., Hyde, M., \& Blane, D. B. (2004). Quality of life in the third age: Key predictors of the CASP-19 measure. Ageing \& Society Special Issue: Understanding Quality of Life in Old Age, 24, 693-708. doi:10.1136/jech.2005.040071

Wilhelmson, K., Andersson, C., Waern, M., \& Allebeck, P. (2005). Elderly people's perspectives on quality of life. Aging \& Society, 25, 585-600. doi:10.1017/S0144686X05003454

Wrosch, C., Shultz, R., \& Heckhausen, J. (2004). Health stresses and depressive symptomatology in the elderly: A control-process approach. Current Directions in Psychological Science, 13, 17-20. doi:10.1111/j.0963-7214.2004.01301005.x

Wymer, W. (2011). Gender differences in social support in the decision to volunteer. International Review on Public and Nonprofit Marketing, 9, 19-26. doi:10.1007/s12208-011-0072-y

Yates, L. B., Djousse, L., Kurth, T., Buring, J. E., \& Graziano, J. M. (2008). Exceptional longevity in men: Modifiable factors associated with survival and function to age 90 years. Archives of Internal Medicine, 168, 284-290. doi:10.1001/archinternmed.2007.77

Young, F. W., \& Glasgow, N. (1998). Voluntary social participation and health. Research on Aging, 20, 339-362. doi:10.1177/0164027598203004 